\title{
亲核型和自由基型七氟异丙氧基化试剂的设计和反应
}

\author{
邓志杰汤平平* \\ (南开大学化学学院 元素有机化学国家重点实验室 天津 300071)
}

\section{Design and Reaction of Nucleophilic and Radical Heptafluoroisopropoxylation Reagents}

\author{
Deng, Zhijie Tang, Pingping* \\ (State Key Laboratory and Institute of Elemento-Organic Chemistry, Nankai University, Tianjin 300071)
}

氟烷基醚官能团是有机合成中一类重要的合成单 元，作为含氟官能团的一种，已在构建药物分子及材料 分子等方面引起了广泛关注 ${ }^{[1]}$. 与非氟烷基梄类官能团 相比, 将氟烷基醚引入到有机分子中, 可以很好地提高 分子的脂溶性和代谢稳定性 ${ }^{[2]}$. 近年来, 氟烷基醚类化 合物的合成主要是在单氟甲基、二氟甲基、三氟甲基醚 等简单氟烷基醚上取得了巨大进展，而对于复杂的如七 氟异丙基醚类化合物的合成却鲜有报道. 七氟异丙基具 有独特的物理化学性质, 如优异的亲脂性、强的吸电子 能力以及大的空间位阻 ${ }^{[2]}$, 这些突出的性质使得七氟异 丙基在现有的临床药物 ${ }^{[3]}$ 以及农用化学品分子 ${ }^{[4]}$ 中都有 广泛的应用. 依据氟烷基官能团(如 $\mathrm{CF}_{3}$ ) 以及简单氟烷 基醚官能团(如 $\mathrm{OCF}_{3}$ )在药物发现中的重要作用 ${ }^{[5]}$, 化学
家相信复杂氟烷基醚官能团七氟异丙氧基 $\left[\mathrm{OCF}\left(\mathrm{CF}_{3}\right)_{2}\right]$ 将是一类极具开发潜力的含氟官能团, 可以为现有药物 分子生物活性的优化以及新药的开发提供极大的帮助.

目前，已报道的七氟异丙基梄类化合物极少，这可 能与合成方法匮乏有关. 合成难点主要在于七氟异丙氧 基负离子极度不稳定，容易分解成全氟丙酮和氟负离 子; 另外, 这种不稳定性也体现在与过渡金属结合之后 容易发生 $\beta$-氟消除，从而不利于通过过渡金属催化引入 七氟异丙氧基. 一般的合成方法是使用金属氟盐与六氟 丙酮反应原位生成七氟异丙氧基负离子 ${ }^{[6]}$ ，随之发生亲 核取代反应生成七氟异丙基醚类化合物，但该方法受限 于气态且剧毒的六氟丙酮的使用. 最近, Ngai 课题组 ${ }^{[7]}$ 报道了 $N$-芳基- $N$-羊釡基酰胺化合物与 $\operatorname{ICF}\left(\mathrm{CF}_{3}\right)_{2}$ 作用, 得

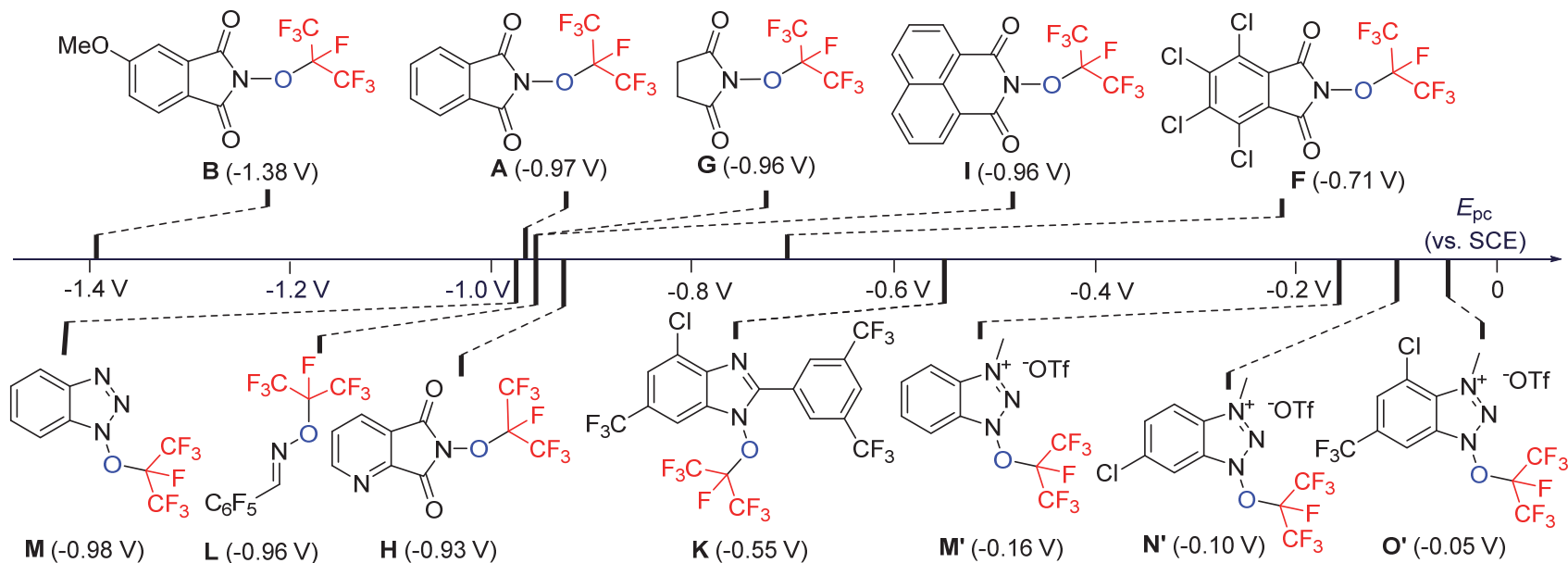

图 $1 N-\mathrm{OCF}\left(\mathrm{CF}_{3}\right)_{2}$ 试剂的还原电势

Figure 1 Reduction potentials of $N-\mathrm{OCF}\left(\mathrm{CF}_{3}\right)_{2}$ reagents

* Corresponding author. E-mail: ptang@nankai.edu.cn. Published online November 24, 2021. 
到 $\mathrm{OCF}\left(\mathrm{CF}_{3}\right)_{2}$ 迁移的产物; 胡金波课题组 ${ }^{[8]}$ 报道了原位 产生苯炔与 $\mathrm{BzOCF}\left(\mathrm{CF}_{3}\right)_{2}$ 反应生成溴代七氟异丙氧基苯 产物. 这两种合成方法的底物适用性都非常局限. 中国 科学院上海有机化学研究所有机氟化学重点实验室卿 凤翎课题组认为, 可以通过发展新的试剂和拓展新的合 成方法实现七氟异丙氧基醚类化合物的多样性合成.

近日, 该研究团队使用 $\operatorname{AgCF}\left(\mathrm{CF}_{3}\right)_{2}$ 与含 $N-\mathrm{OH}$ 的底 物发生反应，合成了多种操作简便、稳定和易保存的酰 胺、肟和唑类 $N-\mathrm{OCF}\left(\mathrm{CF}_{3}\right)_{2}$ 试剂 ${ }^{[9]}$, 并通过循环伏安法 对其还原电势进行了测定(图 1). 研究发现, 还原电势低 于 $-0.8 \mathrm{~V}$ 的 $N-\mathrm{OCF}\left(\mathrm{CF}_{3}\right)_{2}$ 试剂易裂解产生氮自由基和 $\mathrm{OCF}\left(\mathrm{CF}_{3}\right)_{2}$ 负离子, 而还原电势高于 $-0.8 \mathrm{~V}$ 的 $N-$ $\mathrm{OCF}\left(\mathrm{CF}_{3}\right)_{2}$ 试剂易裂解产生氮负离子和 $\mathrm{OCF}\left(\mathrm{CF}_{3}\right)_{2}$ 自由 基.

作者分别对这两种类型的 $\mathrm{N}-\mathrm{OCF}\left(\mathrm{CF}_{3}\right)_{2}$ 的反应性 进行了考察(图 2). 研究发现, 亲核型 $N-\mathrm{OCF}\left(\mathrm{CF}_{3}\right)_{2}$ 试剂 A 参与的亲核取代反应, 其底物适用于烷基碘化物、溴 化物、甲磺酸酯以及对甲苯磺酸酯等. 该类反应官能团 兼容性好，可用于复杂药物分子如艾地苯醌、Ru58841、 奥培米芬等的后期七氟异丙氧基化修饰. 自由基型 $N-\mathrm{OCF}\left(\mathrm{CF}_{3}\right)_{2}$ 试剂 $\mathbf{O}^{\prime}$ 参与的自由基反应, 在光氧化还原
条件下，官能团兼容性很好，如含有卤素、羰基、酯基、 氰基和硝基等基团的底物都能以中等至良好的收率得 到目标产物，并且该反应能兼容如噻吩、吡唑、咪唑、 噻唑和哒嗪等多种杂环。当底物含有两个芳环时，七氟 异丙氧自由基选择性地进攻富电子芳环。值得注意的 是， $\mathrm{X}$ 射线单晶衍射表明，七氟异丙氧基芳基醚中七氟 异丙氧基与芳环采取了近乎垂直的构象，这种特殊的结 构有利于增加分子与目标靶点的亲和力, 在药物发现中 可能会有很好的应用.

卿凤翎团队设计合成了一系列新颖的亲核型和自 由基型 $\mathrm{N}-\mathrm{OCF}\left(\mathrm{CF}_{3}\right)_{2}$ 试剂. 在亲核型七氟异丙氧基试剂 的作用下，实现了各种烷基卤的亲核七氟异丙氧基化反 应，并能拓展至烷基醇的脱羟七氟异丙氧基化和烯烃的 碘化七氟异丙氧基化. 在自由基型七氟异丙氧基试剂的 作用下，实现了(杂)芳烃 $\mathrm{C}-\mathrm{H}$ 键的七氟异丙氧基化反 应和烯烃的氢化七氟异丙氧基化反应，这也是首例自由 基型七氟异丙氧基化反应. 该类 $N-\mathrm{OCF}\left(\mathrm{CF}_{3}\right)_{2}$ 试剂参与 的化学反应，反应条件温和，底物适用广泛，并且可用 于复杂药物分子后期直接引入七氟异丙氧基, 有望在药 物合成领域和生物化学研究中发挥重要作用.

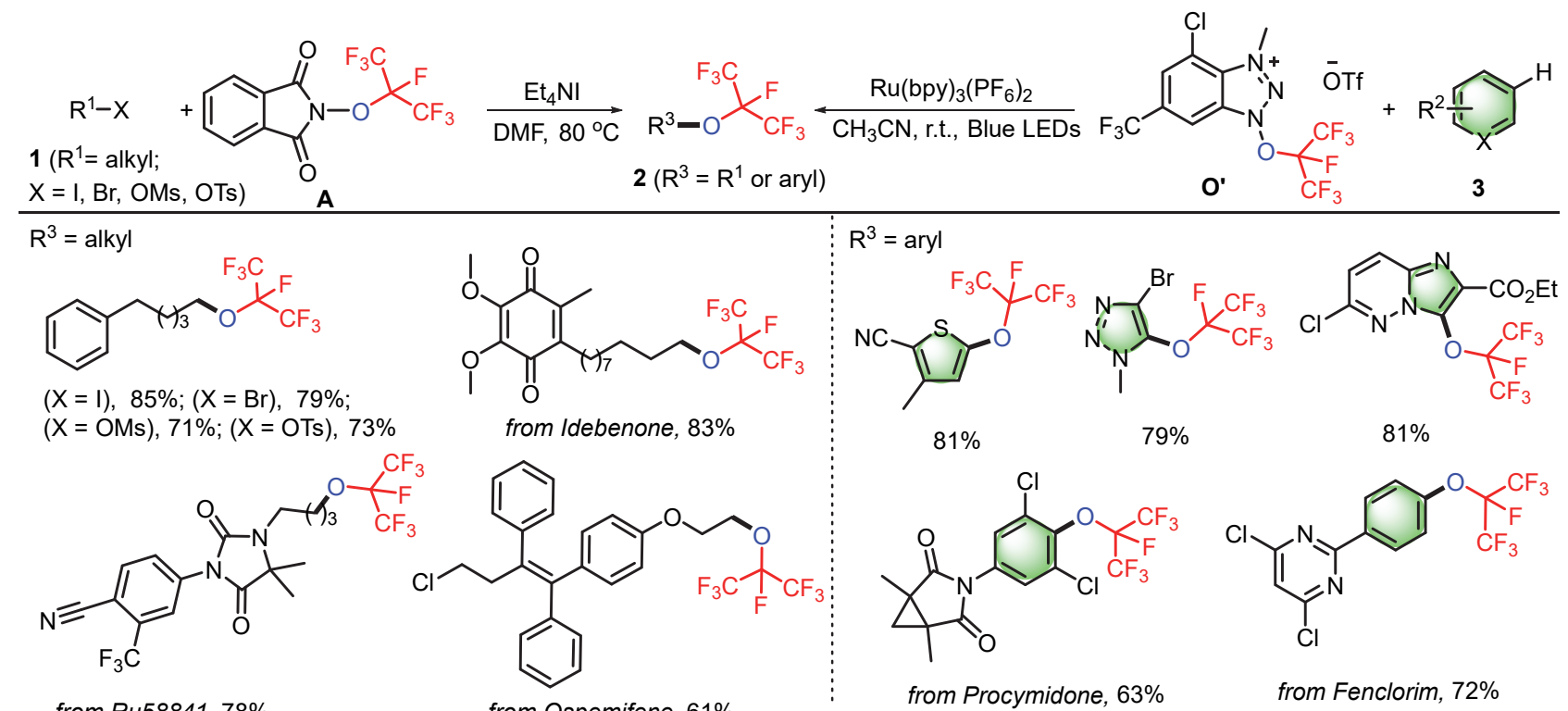

图 2 亲核型和自由基型 $N-\mathrm{OCF}\left(\mathrm{CF}_{3}\right)_{2}$ 试剂参与的反应

Figure 2 Reactions with nucleophilic and radical $N-\mathrm{OCF}\left(\mathrm{CF}_{3}\right)_{2}$ reagents

\section{References}

[1] Leroux, F.; Jeschke, P.; Schlosser, M. Chem. Rev. 2005, 105, 827.

[2] Hansch, C.; Leo, A.; Unger, S. H.; Kim, K. H.; Nikaitani, D.; Lien, E. J. J. Med. Chem. 1973, 16, 1207.

[3] Eignerová, B.; Sedlák, D.; Dračínský, M.; Bartůněk, P.; Kotora, M. J. Med. Chem. 2010, 53, 6947.

[4] Ogawa, Y.; Tokunaga, E.; Kobayashi, O.; Hirai, K.; Shibata, N. iS- cience 2020, 23, 101467.

[5] Inoue, M.; Sumii, Y.; Shibata, N. ACS Omega 2020, 5, 10633.

[6] Chambers, R. D.; Korn, S. R.; Sandford, G. J. Fluorine Chem. 1994, 69, 103 .

[7] Lee, J. W.; Ngai, M.-Y. Chem. Sci. 2017, 8, 6066

[8] Zhou, M.; Ni, C.; Hu, J. B. J. Am. Chem. Soc. 2018, 140, 6801.

[9] Tong, C. L.; Xu, X, H.; Qing, F. L. Angew. Chem., Int. Ed. 2021, 60,2 . 